\title{
Learning from Crisis: a Multicentre Study of Oncology Telemedicine Clinics Introduced During COVID-19
}

\author{
Michael Grant ${ }^{1,2,3} \cdot$ Helen Hockings ${ }^{2} \cdot$ Maria Lapuente $^{1,2} \cdot$ Philip Adeniran $^{1,2} \cdot$ Rabiah Abbas Saud $^{1,2} \cdot$ \\ Anjali Sivajothi ${ }^{1,2} \cdot$ Jubel Amin $^{1,2} \cdot$ Shanthini M. Crusz ${ }^{2} \cdot$ Sukaina Rashid $^{2} \cdot$ Bernadette Szabados $^{1,2} \cdot$ Paula Wells $^{2}$. \\ Ekaterini Boleti ${ }^{3} \cdot$ Thomas B. Powles ${ }^{1,2}$
}

Accepted: 7 June 2021 / Published online: 2 July 2021

(c) American Association for Cancer Education 2021

\begin{abstract}
The COVID-19 pandemic has necessitated adaptation of cancer patient care. Oncology patients who contract COVID-19 have poor outcomes. Telemedicine clinics (teleclinics) have been introduced for cancer patients to reduce the risk of horizontal transmission at St. Bartholomew's Hospital and The Royal Free Hospital in London. Teleclinics have become routine in many specialities; however, inclusion in oncology care was not standard prior to the pandemic. A mixed-methods survey was designed and delivered to cancer patients $(\mathrm{n}=106)$ at St. Bartholomew's Hospital and The Royal Free Hospital who had transitioned to teleclinics in March 2020. The survey explored patients' perceptions of this format. In total, 96 (90.5\%) patients consented to take part, across a range of tumour types. Overall, respondents reacted favourably to the format of the teleclinics, with $90.6 \%$ of respondents (87/96) stating they would utilise teleclinics beyond the pandemic. Additionally, a survey was distributed to clinicians delivering these teleclinics $(n=16)$ to explore previous training in, perceptions of, and lessons learned from the introduction of telemedicine. Results suggest patients are accepting of teleclinic use for most clinical purposes. Teleclinic implementation affords benefits to cancer patient care both during and after COVID-19, but there is an urgent need for telemedicine education in oncology specialty training.
\end{abstract}

Keywords Cancer $\cdot$ COVID-19 $\cdot$ Telemedicine $\cdot$ Patient experience $\cdot$ Evidence-based care

Thomas B. Powles

Thomas.powles1@nhs.net

Michael Grant

michael.grant13@nhs.net

Helen Hockings

h.hockings@nhs.net

Maria Lapuente

m.lapuente@nhs.net

Philip Adeniran

p.adeniran@nhs.net

Rabiah Abbas Saud

rabiah.saud@nhs.net

Anjali Sivajothi

anjali.sivajothi@nhs.net

Jubel Amin

jubel.amin@nhs.net

Shanthini M. Crusz

shanthini.crusz@nhs.net
Sukaina Rashid

sukaina.rashid1@nhs.net

Bernadette Szabados

bernadett.szabados@nhs.net

Paula Wells

paula.wells6@nhs.net

Ekaterini Boleti

ekaterini.boleti@nhs.net

1 Barts Cancer Institute, Bart's and The London

School of Medicine and Dentistry, Queen Mary

University of London, Charterhouse Square, Barbican, London EC1M 6BE, UK

2 Department of Oncology, St. Bartholomew's Hospital, Bart's Health NHS Trust, London, UK

3 Specialist Kidney Cancer Unit, Royal Free Hospital, Royal Free NHS Foundation Trust, London, UK 


\section{Introduction}

COVID-19 is challenging healthcare systems globally, impacting on services including oncology [1]. As understanding of COVID-19 develops, early evidence suggests cancer patients are at an increased risk of morbidity and mortality [2]. This highlights the need to reduce the physical presence of oncology patients within hospitals [2]. However, given that the duration of the current pandemic is unclear, there is an urgent need to develop systems to monitor and treat cancer patients remotely. Telemedicine technologies may present an avenue for continuing urgent oncology care for patients, whilst minimising the risk of nosocomial infection [2].

St. Bartholomew's Hospital and The Royal Free Hospital are specialist cancer centres in London [3]. Both hospitals have introduced telephone-based telemedicine clinics (teleclinics) during the initial weeks of the pandemic to ensure continuity of care whilst reducing risk for cancer patients.

Many specialties, in particular General Practice, have seen the gradual incorporation of telemedicine into core services over the past decade. This is in line with key recommendations of long-term UK healthcare strategy to reduce the burden of outpatient appointments [4]. However, this evolution in outpatient care has eluded the majority of cancer services and oncology clinicians do not routinely receive training in telemedicine. This is despite growing evidence that cancer patients are receptive to the format of teleclinics, with some studies even demonstrating improved outcomes in comparison to face-to-face (F2F) care [5]. As telemedicine is not typically integrated in many oncology services within the NHS, the levels of training in conducting remote reviews amongst oncology clinicians are unknown. Hence, it is important to ascertain insights and lessons learned from these clinicians during the rapid implementation of this modality during the pandemic and how these can be harnessed for the development of educational tools for future oncology clinicians.

In the UK, the General Medical Council (GMC) guides the undergraduate curriculum of medical schools. In their latest guidance for outcomes in medical graduates, communication skills pertaining to telemedicine were introduced [6]. However, in 2018, the UK Council of Clinical Communication noted a lack of undergraduate teaching and exposure to telemedicine technologies in UK Medical Schools [7]. This is despite evidence that interaction with these technologies during undergraduate medical training contributes to improved core competencies and higher quality patient care [8]. For those in Medical Oncology speciality training, the curriculum set out by the Joint Royal Colleges of Physicians Training Board includes that oncologists should be able to "discuss the application of telemedicine or telecare to clinical practice" [9]. However, this is not routinely assessed nor is any formal training in telemedicine required for completion of this postgraduate speciality programme.

Even prior to the COVID-19 pandemic, telemedicine has been a booming component of practice. In 2019, the global telemedicine market was estimated to have a value of over $\$ 41$ billion [10]. However, the integration of telemedicine into medical education and training is not widespread. Despite this, smaller studies of medical trainees who completed curricula with integrated telemedicine training reported improved attainment of core competencies in patient care, medical knowledge, and practice-based learning [11-13].

Prior to the pandemic, concerted efforts into the development of telemedicine have traditionally focused on "the big five" diseases identified by the World Health Organization, namely diabetes mellitus, cardiovascular and chronic respiratory diseases, cancer, and stroke [14]. Whilst strides have been many in many of these areas, studies of telemedicine use in oncology have been met with caution and are considered still in their nascent phase [15]. However, with lessons learned from other specialities and the necessitated implementation of telemedicine in oncology during the pandemic, how can we best educate oncology clinicians to deliver highquality healthcare via teleclinics in the "new normal"?

This study sought to elucidate the perceptions and opinions of cancer patients at St. Bartholomew's Hospital and The Royal Free Hospital in regard to this recent and rapid transition to teleclinics. In addition, a subsequent survey of clinicians involved with the delivery of teleclinics was completed, after the presentation of initial survey results to stakeholders at both sites. The aims were to evaluate patient and clinician experiences of this format and to explore attitudes toward aspects of telemedicine in cancer care, in order gain insights and support the development of educational information for future oncology clinicians utilising telemedicine.

\section{Methods}

Attending oncology physicians identified patients $(\mathrm{n}=106)$ at St. Bartholomew's Hospital and The Royal Free Hospital whom received at least one teleclinic session, in lieu of a scheduled F2F clinic due to COVID-19, between 7/3/20 and 2/4/20. A telephone-based, mixed-methods survey was designed with input from the multidisciplinary team (MDT). This consisted of collection of demographic information, a mix of numerical scales ( 0 to 10 , with 10 being strongest agreement with statement) and binary closed questions for teleclinic perceptions, and a final open question seeking 
suggestions on how to improve the service (Supplementary Data 1). Participation was voluntary and the survey was delivered to consenting patients by clinical members of the oncology team within 2 weeks of their most recent teleclinic. Participants were made aware that feedback was anonymous. The survey was registered as a clinical audit at both sites with the additional intention of comparing current performance against NHS England guidelines-released in the same month-regarding remote patient review during the pandemic [16].

The survey collected demographic information pertaining to the subject (hospital site, tumour site, gender, age, time since diagnosis, current disease status [based on most recent cross-sectional imaging], line of treatment, duration of current treatment/observation, performance status [ECOG], current frequency of visits, and participant selfassessed possession of fluent English and/or normal hearing). The teleclinic format was assessed on satisfaction with format, adequate time provision, ability to ask questions, sensitive/supportive delivery of information, willingness to have teleclinics outside of the current pandemic, and willingness to discuss clinical topics by teleclinic (specifically favourable/ "good" and unfavourable/ "bad" blood results, favourable/ "good" and unfavourable/ "bad" scan results, symptom review, and discussion of/consent for new treatment). Preferred amount of notice given prior to switching to/from teleclinic and COVID-19's impact on their treatment (change to type/frequency of treatment) was also noted. At the end of the survey, patients were asked an open question, prompting any additional suggestions they had to improve the format.

Following this initial survey and the presentation of its results to local stakeholders, a subsequent survey was designed and delivered to oncology clinicians at both sites who had been involved in the delivery of oncology teleclinics. An internet-based (SurveyMonkey ${ }^{\mathrm{TM}}$ ), mixed-methods survey was designed with input from attending oncology physicians. This consisted of collection of job role, a Likert scale (ranging from strongly disagree to strongly agree) and binary closed questions regarding teleclinic experience, and a final open question seeking suggestions on specifics to be included in training for oncology teleclinic training. Participation was voluntary and the survey was delivered to clinicians within the oncology team following presentation of results from the initial patient-focused survey. Participants were made aware that feedback was anonymous.

\section{Results}

All of the patients identified $(\mathrm{n}=106)$ were contacted by telephone. In total, $96(90.5 \%)$ of those contacted consented to take part. These included renal $(n=20)$, bladder $(\mathrm{n}=13)$, prostate $(\mathrm{n}=8)$, melanoma $(\mathrm{n}=16)$, lung $(\mathrm{n}=12)$, testicular $(n=8)$, breast $(n=16)$, and lymphoma $(n=3)$ cancer patients (Table 1). Forty-two were female and the median age of participants was 64 (28-90). The majority $(n=68)$ of patients were on systemic anti-cancer therapy (SACT), whilst 18 patients were on follow-up after radical surgery and 10 on watchful waiting.

In relation to the audit component of this study, both sites performed strongly in meeting criteria of the planning guide outlined by NHS England [16]. St. Bartholomew's Hospital and The Royal Free Hospital met 37 and 38 , respectively, of the 40 criteria within this guide. Interestingly, both sites' oncology departments missed two criterions relevant to this study, namely "All staff have been trained in the new system and are competent" and "A patient/layperson has tested the process", at time of initial survey.

Overall, participants' opinions of the teleclinic format were positive. In the numerical scale questions (i.e. agreement on a scale of $0-10$ regarding satisfaction with format, time allotted to session, ability to ask questions, and sensitivity/supportiveness), the median score for all was the maximum of 10 with a mean of 38.2 in the compound score (i.e. accumulative rating out of 40 from all four numerical scale questions). In the binary (Yes/No) questions, 87 participants (90.6\%) stated they would be happy to have teleclinics outside of the current pandemic. In the questions relating to what type of information patients would be willing to receive during teleclinics, patients responded positively to receiving bloods test results irrespective of the results (both "Favourable" [100\%] and "Unfavourable" [86.5\%]) and "Favourable" scan results (90.6\%). However, patients were less likely to want to receive "Unfavourable" scan results $(57.3 \%)$ or discuss new treatments (50\%). Additionally, the majority $(n=59)$ of participants stated that they would prefer $48-h$ notice prior to a F2F clinic being converted to a teleclinic, or vice versa. Lung cancer patients had the lowest, average compound score and urothelial cancer patient reported the lowest willingness to incorporate telemedicine clinics in their care outside of COVID-19; however, there was no statistically significant variance between tumour groups in these results (ANOVA, $p=0.28$ and $p=0.99$ respectively) (Fig. 1). There was no statistical correlation between age and willingness to have teleclinics (Pearson's $\mathrm{R}, \mathrm{p}=0.33$ ).

Patients were also specifically asked if the COVID-19 pandemic had impacted their regular treatment/follow-up, of which $33.3 \%$ (32/96) stated it had. These responses were correlated to patient medical records. Changes to treatment included 17 (53.1\%) decreases in frequency of SACT, $11(34.4 \%)$ delays in SACT/radical surgery, three $(9.4 \%)$ changes of SACT type, and one $3.1 \%$ ) cessation of SACT (Table 1). This one cessation of treatment was due to the closure of an adjuvant clinical trial. 


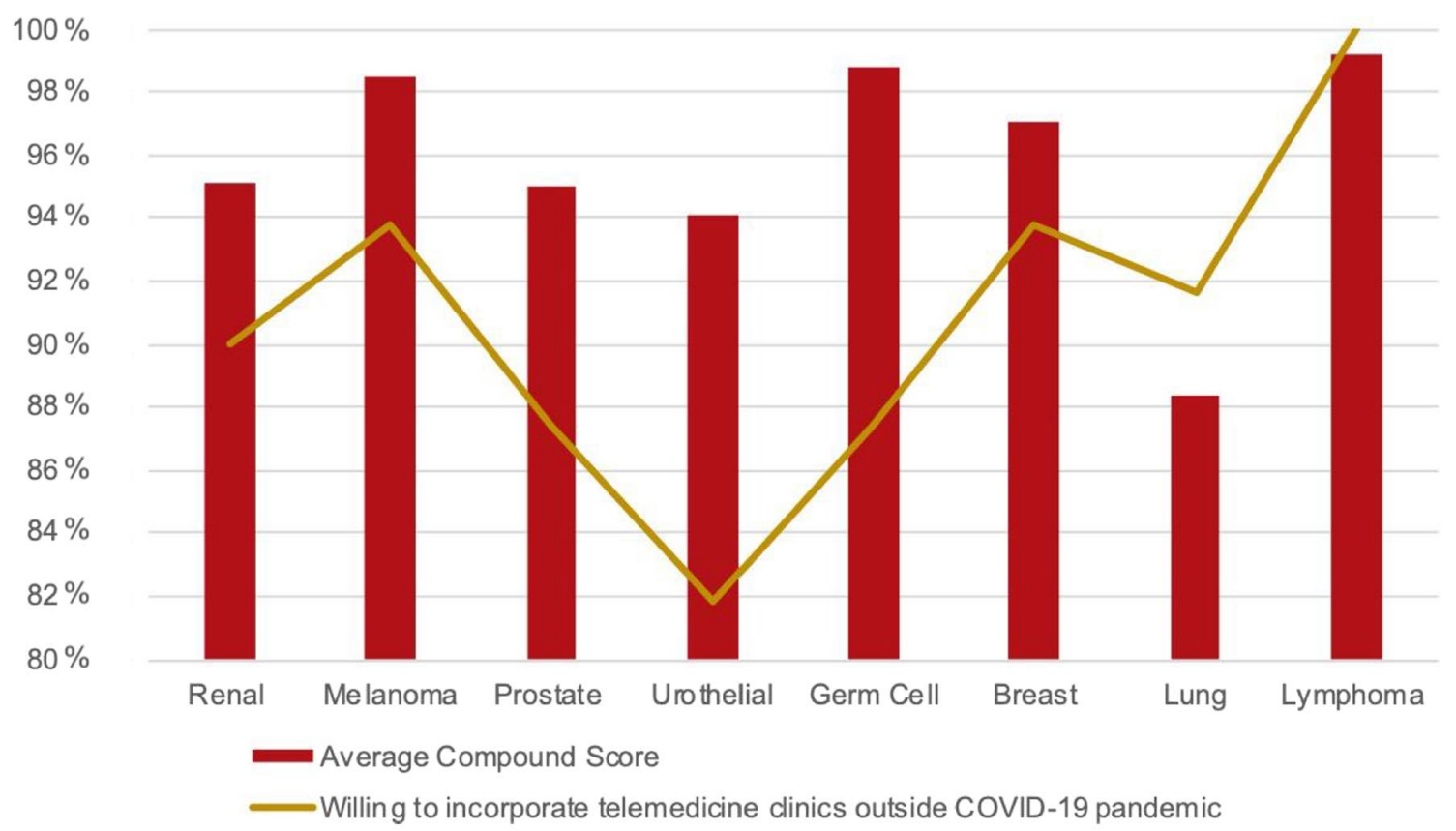

One-Way ANOVA [Average \pm Standard Deviation] of compound score (/40)

60

40

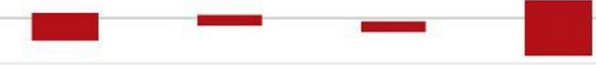

20

0

One-Way ANOVA [Average \pm Standard Deviation] of willing to incorporate telemedicine (binary)

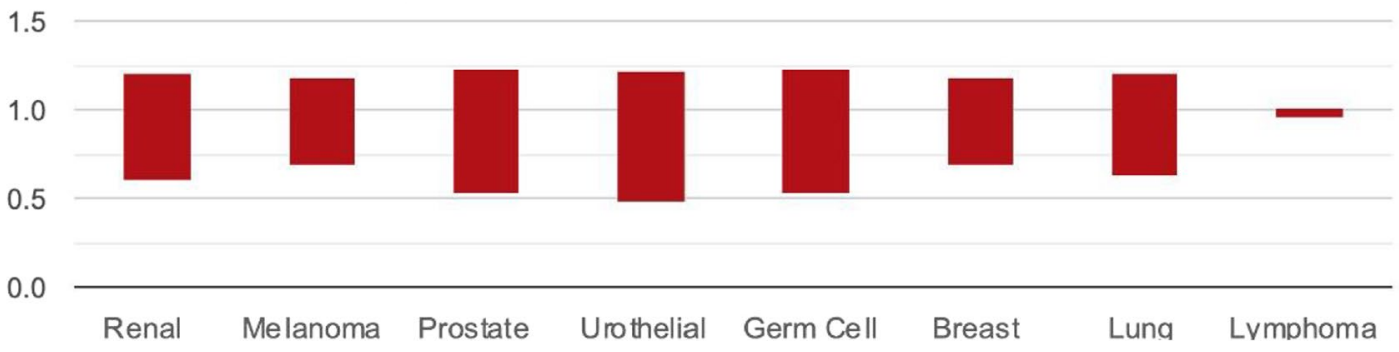

Fig. 1 Average compound scores from numerical questions and willingness to incorporate telemedicine clinics into care outside of the COVID19 pandemic by tumour type, alongside ANOVA for each $(p=0.28$ and $p=0.99$, respectively)

When asked for suggestions to improve the service, 10 participants provided a response. These responses underwent thematic analysis [17]. This revealed three themes: (1) patients felt teleclinics saved time and reduced fatigue from travel, (2) patients were happy to have teleclinics to confirm SACT but would like availability of clinician review if requested, (3) patients with hearing/language difficulties may struggle with telephone-based teleclinics.

In relation to the subsequent survey which focused on clinicians involved with delivering the teleclinics at either site $(n=16), 15$ clinicians completed the survey (response rate of 93.6\%) (Table 2). Of these respondents, 13 were oncology physicians and two were oncology nurse specialists (CNS). Only two clinicians were regularly involved in conducting teleclinics prior to the pandemic, only one of which had received formal training. The single respondent who had received training stated that this consisted of training videos provided during a previous emergency medicine rotation to aid in triaging patients.

There were two responses to the open text question "What other, if any, training do you believe would be of benefit to oncology clinicians prior to performing telemedicine clinics?", 
Table 1 Results of patient telephone survey

\begin{tabular}{|c|c|}
\hline \multicolumn{2}{|l|}{ Patient details } \\
\hline Patients contacted & $\mathrm{n}=106$ \\
\hline Consented to survey & $\mathrm{n}=96$ \\
\hline \multicolumn{2}{|l|}{ Tumour type $(\mathrm{N}=\mathrm{x})$} \\
\hline $\begin{array}{l}\text { Renal } \\
\text { Bladder } \\
\text { Prostate } \\
\text { Melanoma } \\
\text { Lung } \\
\text { Testicular } \\
\text { Breast } \\
\text { Lymphoma }\end{array}$ & $\begin{array}{l}20 \\
13 \\
8 \\
16 \\
12 \\
8 \\
16 \\
3\end{array}$ \\
\hline \multicolumn{2}{|l|}{ Time since diagnosis (months) } \\
\hline $\begin{array}{l}<3 \text { months } \\
3-6 \text { months } \\
6-12 \text { months } \\
>12 \text { months }\end{array}$ & $\begin{array}{l}7 \\
8 \\
12 \\
72\end{array}$ \\
\hline \multicolumn{2}{|l|}{ Gender $(\mathrm{N}=\mathrm{x})$} \\
\hline $\begin{array}{l}\text { Male } \\
\text { Female }\end{array}$ & $\begin{array}{l}54 \\
42\end{array}$ \\
\hline \multicolumn{2}{|l|}{ Age (years) } \\
\hline Median, [range] & $64,[28-90]$ \\
\hline \multicolumn{2}{|c|}{ Disease status from most recent results/imaging } \\
\hline $\begin{array}{l}\text { No recurrence } \\
\text { Complete response } \\
\text { Partial response } \\
\text { Stable disease } \\
\text { Progressive disease }\end{array}$ & $\begin{array}{l}18 \\
17 \\
8 \\
27 \\
23\end{array}$ \\
\hline \multicolumn{2}{|l|}{ Treatment modality $(\mathrm{N}=\mathrm{x})$} \\
\hline $\begin{array}{l}\text { SACT } \\
\text { Post-surgical surveillance } \\
\text { Watchful waiting }\end{array}$ & $\begin{array}{l}68 \\
18 \\
10\end{array}$ \\
\hline \multicolumn{2}{|l|}{ Number of lines of SACT } \\
\hline Median, [range] & $1,[0-6]$ \\
\hline \multicolumn{2}{|c|}{ Duration of current treatment (months) } \\
\hline Median, [range] & $4,[0-51]$ \\
\hline \multicolumn{2}{|l|}{ ECOG } \\
\hline Median, [range] & $1,[0-3]$ \\
\hline \multicolumn{2}{|c|}{ Current frequency of visits (weeks) } \\
\hline Median, [range] & $4,[2-28]$ \\
\hline \multicolumn{2}{|l|}{ Fluent English } \\
\hline Number, [\%] & $94,[97.9 \%]$ \\
\hline
\end{tabular}

Telemedicine

How much do you agree with the following (0-10): Median, [range]

I was satisfied with the format

$10,[5-10]$

There was adequate time given to the consultation

$10,[4-10]$

I felt able to ask questions

$10,[2-10]$

Information was delivered in a sensitive/supportive manner

$10,[2-10]$

Compound score (/40)

$40,[15-40]$

Would you be happy to have teleclinics outside of the current pandemic?

Number responding "Yes", [\%]

$87,[90.6 \%]$

Which would you be happy to have over the phone?

Number responding "Yes", [\%]

Blood results (Favourable)

$96,[100.0 \%]$ 
Table 1 (continued)

\begin{tabular}{ll}
\hline Patient details & \\
\hline Blood results (Unfavourable) & $83,[86.5 \%]$ \\
\hline Scan results (Favourable) & $87,[90.6 \%]$ \\
Scan results (Unfavourable) & $55,[57.3 \%]$ \\
Symptom review (e.g. pain, medications, treatment toxicity) & $71,[74.0 \%]$ \\
Discussion of new treatment/consent & $48,[50.0 \%]$ \\
How much notice would you like if a clinic was to be changed to tele from face-to-face or vice versa? \\
(N=x) \\
$0-24$ h & 12 \\
$24-48$ h & 47 \\
$2-7$ days & 32 \\
$1-2$ weeks & 5 \\
$>2$ weeks & 0 \\
Did your cancer treatment change as a result of COVID (Yes/No) & $32,[33.3 \%]$ \\
Number, [\%] & \\
If so, how? (N=x)AQ & 11 \\
Delay to treatment (including surgery) & 17 \\
Change of treatment frequency & 3 \\
Change of treatment type & 1 \\
Stop treatment &
\end{tabular}

which were "direct supervision of juniors by consultant" and "Guidance on how often people on treatment should be seen F2F".

In response to the multiple-choice question "What form would best suit telemedicine training for oncology clinicians?", answers included senior supervised telemedicine clinics with feedback $(4,26.7 \%)$, online module $(3,20.0 \%)$, inclusion in higher speciality training (e.g. formal assessment within medical/clinical oncology speciality registrars or CNS trainees) $(1,6.7 \%)$, departmental teaching $(6,40.0 \%)$, and trust-level mandatory training $(1,6.7 \%)$.

\section{Discussion}

Results suggest that cancer patients are amenable to the use of teleclinics as part of their routine care. However, there is an understandable desire to have access to clinical review and physician contact in certain circumstances. Whilst this evidence supports a "blended" model of outpatient care (combining F2F with aspects of telemedicine when appropriate), an issue arises as patients assume that if they are scheduled for a F2F clinic, then they will be receiving unfavourable results and vice versa [5, 18].

In this study, whilst a range of tumour groups were surveyed, a number of cancer types (e.g. gastrointestinal and brain) are not represented and may differ in response. Additionally, the validity of this survey may be limited by COVID-19 itself. It is possible that anxiety surrounding the pandemic may cause patients to under-report symptoms in teleclinics, with the purpose of avoiding requests to attend hospital for review. However, these results are in keeping with work conducted prior to the COVID-19 crisis [5].

The telephone format of the teleclinics implemented may be an issue for those with hearing difficulties or limited English. Only two respondents reported they were affected by this; however, adaptations would need to be made for such patients in future. This may involve the use of teleconference technology to include translators/interpreters in the consultation.

Whilst the majority had the survey delivered in the days following teleclinic, some patients were asked to respond to the survey immediately after their session. This will have limited some patients' ability to reflect on the format. Ideally, this survey would have been conducted by interview after a specific number of teleclinics to allow familiarity with the format, but this was not possible to achieve with significant numbers of participants due to variance in clinic frequency between patients and limitations of patient contact due to the pandemic.

The rationale for minimising vulnerable cancer patients' contact with clinical environments during a pandemic is strong; this may also apply outside of a pandemic backdrop [19]. Teleclinics could reduce the number of F2F visits required and widen access to specialist centres, which would otherwise require impractical or costly commuting [20].

Teleclinics may play a role in improving access to specific clinicians, extended members of the MDT (e.g. nurse specialists), clinical psychology appointments, and cancer clinical trials [20]. However, of note, none of the clinical teams involved with this survey had received any formal training in telemedicine. 
Table 2 Results of clinician survey. SACT, systemic anti-cancer therapy

Clinician survey Likert scale questions $(\mathrm{n}=15)$

During the initial utilisation of telemedicine due to COVID-19, I felt fully equipped to carry out teleclinics

Strongly disagree

$0(0.0 \%)$

Disagree

$4(26.7 \%)$

Neither agree nor disagree

$4(26.7 \%)$

Agree

Strongly agree

$6(40.0 \%)$

Telemedicine clinics have added to department workload

Strongly disagree

$1(6.7 \%)$

Disagree

$0(0.0 \%)$

Neither agree nor disagree

$7(46.7 \%)$

Agree

$4(26.7 \%)$

Strongly agree

$4(26.7 \%)$

Telemedicine clinics result in similar outcomes as face-to-face clinics for the majority of patients

Strongly disagree

$0(0.0 \%)$

Disagree

Neither agree nor disagree

Agree

Strongly agree

$0(0.0 \%)$

$4(26.7 \%)$

$0(0.0 \%)$

$11(73.3 \%)$

$0(0.0 \%)$

Telemedicine should have a place in routine oncology care following the resolution of the COVID19 pandemic

Strongly disagree

$0(0.0 \%)$

$0(0.0 \%)$

Disagree

$0(0.0 \%)$

Neither agree nor disagree

$11(73.3 \%)$

Strongly agree

$4(26.7 \%)$

My opinion of telemedicine has improved since using it during COVID19

Strongly disagree

$0(0.0 \%)$

Disagree

$0(0.0 \%)$

Neither agree nor disagree

$2(13.3 \%)$

Agree

$11(73.3 \%)$

Strongly agree

$2(13.3 \%)$

The inability to perform physical examination in telemedicine clinics is a significant limiting factor for a majority appointments

Strongly disagree

$0(0.0 \%)$

$7(46.7 \%)$

$5(33.3 \%)$

Neither agree nor disagree

$3(20.0 \%)$

Agree

$0(0.0 \%)$

Telemedicine appointments should be held at the same time as corresponding face-to-face clinics

Strongly disagree

$0(0.0 \%)$

Disagree

$3(20.0 \%)$

Neither agree nor disagree

$4(26.7 \%)$

Agree

$7(46.7 \%)$

Strongly agree

$1(6.7 \%)$

The current administrative infrastructure for clinics (e.g. booking appointments, outpatient bloods/scans, prescriptions) is capable of dealing with teleclinics efficiently

Strongly disagree

$1(6.7 \%)$

Disagree

$7(46.7 \%)$

Neither agree nor disagree

$2(13.3 \%)$

Agree

$5(33.3 \%)$

Strongly agree

$0(0.0 \%)$

The following types of oncology clinic appointments are suitable for telemedicine:

New diagnosis

Strongly disagree

$13(86.7 \%)$

Disagree

$2(13.3 \%)$

Neither agree nor disagree

$0(0.0 \%)$

Agree

$0(0.0 \%)$

Strongly agree

$0(0.0 \%)$ 
Table 2 (continued)

\begin{tabular}{|c|c|}
\hline \multicolumn{2}{|c|}{ Clinician survey Likert scale questions $(\mathrm{n}=15)$} \\
\hline \multicolumn{2}{|l|}{ Surveillance } \\
\hline Strongly disagree & $0(0.0 \%)$ \\
\hline Disagree & $1(6.7 \%)$ \\
\hline Neither agree nor disagree & $1(6.7 \%)$ \\
\hline Agree & $4(26.7 \%)$ \\
\hline Strongly agree & $9(60.0 \%)$ \\
\hline \multicolumn{2}{|l|}{ Consent to new treatment } \\
\hline Strongly disagree & $4(26.7 \%)$ \\
\hline Disagree & $7(46.7 \%)$ \\
\hline Neither agree nor disagree & $2(13.3 \%)$ \\
\hline Agree & $2(13.3 \%)$ \\
\hline Strongly agree & $0(0.0 \%)$ \\
\hline \multicolumn{2}{|c|}{ Stable disease/continuation of established treatment } \\
\hline Strongly disagree & $0(0.0 \%)$ \\
\hline Disagree & $1(6.7 \%)$ \\
\hline Neither agree nor disagree & $0(0.0 \%)$ \\
\hline Agree & $7(46.7 \%)$ \\
\hline Strongly agree & $7(46.7 \%)$ \\
\hline \multicolumn{2}{|l|}{ Progressive } \\
\hline Strongly disagree & $10(66.7 \%)$ \\
\hline Disagree & $5(33.3 \%)$ \\
\hline Neither agree nor disagree & $0(0.0 \%)$ \\
\hline Agree & $0(0.0 \%)$ \\
\hline Strongly agree & $0(0.0 \%)$ \\
\hline \multicolumn{2}{|l|}{ End-of-life/symptomatic care } \\
\hline Strongly disagree & $3(20.0 \%)$ \\
\hline Disagree & $5(33.3 \%)$ \\
\hline Neither agree nor disagree & $4(26.7 \%)$ \\
\hline Agree & $3(20.0 \%)$ \\
\hline Strongly agree & $0(0.0 \%)$ \\
\hline
\end{tabular}

Cancer patients gave positive feedback regarding the transition to teleclinics for aspects of their care during the pandemic. This is in-keeping with existing literature regarding the incorporation of telemedicine into oncology care. Importantly, this urgent need to shift to remote care for oncology patients has highlighted the lack of training in telemedicine provided at the undergraduate level and in higher oncology training.

Key findings from the clinician survey include the lack of prior training in the conductance of teleclinics, the improved perception of telemedicine following its introduction, and that many teleclinics had similar outcomes to F2F visits. Despite the lack of both prior experience and training, most clinicians felt equipped to perform teleclinics. In combination with the results of the patient survey, there are number of areas of alignment. In particular that teleclinics should continue to form part of oncology patient care following the pandemic but that this modality is more suitable for certain types of patient encounter (e.g. surveillance scans, continuation of treatment). It is these findings that are important to include in future telemedicine education platforms. From clinician feedback, the preference was for specific, oncology department training prior to conducting teleclinics, rather than alternatives such as an online module. Such department teaching sessions should be held at regular intervals to capture new staff members and include information on triaging patients to either telemedicine or F2F appointments. Importantly, training should also be provided in regard to the logistics of remote consultation, e.g. arranging delivery of prescriptions, orchestrating outpatient investigations.

The pandemic has acted as a catalyst for clinicians to embrace modern means of interaction with our patients. The results of this study further demonstrate that cancer patients are amenable to the incorporation of telemedicine into their care. Given this and the on-going need to protect cancer patients from COVID-19, it is of high importance that oncology clinicians are trained to conduct these remote sessions in the most effective manner possible.

Supplementary Information The online version contains supplementary material available at https://doi.org/10.1007/s13187-021-02053-8. 


\section{References}

1. Hollander JE, Carr BG (2020) Virtually perfect? Telemedicine for Covid-19. N Engl J Med.https://doi.org/10.1056/NEJMp 2003539

2. Bersanelli M (2020) Controversies about COVID-19 and anticancer treatment with immune checkpoint inhibitors. Immunotherapy 12(5):269-273. https://doi.org/10.2217/imt-2020-0067

3. Liu WK et al (2020) Cytoreductive nephrectomy in metastatic renal cell carcinoma: outcome of patients treated with a multidisciplinary, algorithm-driven approach.World J Urol.https://doi.org/ 10.1007/s00345-020-03107-0

4. Mole G et al (2019) A service evaluation of specialist nurse telephone follow-up of bowel cancer patients after surgery. $\mathrm{Br}$ J Nurs. 28(19):1234-1238. https://doi.org/10.12968/bjon.2019. 28.19.1234 (https://www.ncbi.nlm.nih.gov/pubmed/31680571)

5. Sirintrapun SJ, Lopez A (2018) (2018) Telemedicine in cancer care. Am Soc Clin Oncol Educ Book 38:540-545. https://doi.org/ 10.1200/EDBK_200141

6. General Medical Council UK (2018) Outcomes for graduates [Internet]. Last accessed 18/08/20. Available from: https://www. gmc-uk.org/education/standards-guidance-and-curricula/stand ards-and-outcomes/outcomes-for-graduates

7. Noble LM, Scott-Smith W, O’Neill B, Salisbury H (2018) Consensus statement on an updated core communication curriculum for UK undergraduate medical education. Patient Educ Couns 101(9):1712-1719. https://doi.org/10.1016/j.pec.2018.04.013

8. Mian A, Khan S (2020) Medical education during pandemics: a UK perspective. BMC Med 18:100. https://doi.org/10.1186/ s12916-020-01577-y

9. Joint Royal Colleges of Physicians Training Board (2017) Specialty training curriculum for medical oncology [Internet]. Last access 18/08/20. Available from: https://www.jrcptb.org.uk/speci alties/medical-oncology

10. Grand View Research. Telemedicine market size, share, and trends analysis report, 2020-2027. Last access 02/04/21. Available from: https://www.grandviewresearch.com/industry-analysis/telemedici ne-industry
11. Jumreornvong O, Yang E, Race J, Appel J (2020) (2020) Telemedicine and medical education in the age of COVID-19. Acad Med 95(12):1838-1843. https://doi.org/10.1097/ACM.00000 00000003711]

12. Boyers LN et al (2015) (2015) Teledermatology as an educational tool for teaching dermatology to residents and medical students. Telemed J E Health 21:312-314

13. American Medical Association (2016) AMA encourages telemedicine training for medical students, residents. Last access 02/04/21. Available from: https://www.ama-assn.org/press-center/press-releases/ ama-encourages-telemedicine-training-medical-students-residents

14. Alwan A (2011) Global status report on noncommunicable diseases 2010. Geneva, Switzerland: World Health Organization; 2011. Last access 02/04/21. Available from: http://www.who.int/ $\mathrm{nmh} /$ publications/ncd_report_full_en.pdf

15. Marzorati C et al (2018) (2018) Telemedicine use among caregivers of cancer patients: systematic review. J Med Internet Res 20(6):e223. https://doi.org/10.2196/jmir.9812]

16. NHS England (2020) Clinical guide for the management of remote consultations and remote working in secondary care during the coronavirus pandemic, version 1. Published 27 March 2020. Last access 02/04/21. Available from: https://www.england.nhs.uk/ coronavirus/wp-content/uploads/sites/52/2020/03/C0044-Speci alty-Guide-Virtual-Working-and-Coronavirus-27-March-20.pdf

17. Guest G, MacQueen KM, Namey EE (2012) Applied thematic analysis. SAGE Publications, Inc. https://doi.org/10.4135/9781483384436

18. den Bakker CM et al (2018) Cancer survivors' needs during various treatment phases after multimodal treatment for colon cancer - is there a role for eHealth? BMC Cancer 18(1):1207. https://doi. org/10.1186/s12885-018-5105-Z

19 Ariza-Heredia EJ, Chemaly RF (2018) Update on infection control practices in cancer hospitals: Infection Control in Cancer. CA Cancer J Clin 68(5):340-355. https://doi.org/10.3322/caac.21462

20. Sharrocks K et al (2014) (2014) The impact of socioeconomic status on access to cancer clinical trials. Br J Cancer 111:1684-1687. https://doi.org/10.1038/bjc.2014.108

Publisher's Note Springer Nature remains neutral with regard to jurisdictional claims in published maps and institutional affiliations. 